\title{
The effect of operations management practices on the competitive advantages of SMEs: A mediating role of supply chain management practices
}

\author{
Tahir Iqbal ${ }^{\mathbf{a}^{*}}$
}

\begin{tabular}{l} 
aImam Abdulrahman Bin Faisal Uni \\
\hline C H R O N I C L E \\
\hline Article history: \\
Received June 30,2020 \\
Received in revised format July 8, \\
2020 \\
Accepted August 302020 \\
Available online \\
September 22020 \\
\hline Keywords: \\
Operations management practices \\
(OM) \\
Competitive advantage \\
Supply chain management \\
practices (SCM) \\
Saudi Arabia \\
Small and medium-sized \\
enterprises (SMEs)
\end{tabular}

\begin{abstract}
A B S T R A C T
The research aimed to evaluate the impact of operations management practices $(\mathrm{OM})$ on the competitive advantage of Saudi Arabian Small and medium-sized enterprises (SMEs). It further aimed to analyse the mediating role of supply chain management practices (SCM). The research design of the study was quantitative, and primary data was gathered using a close-ended survey questionnaire. In this research, 383 participants were recruited belonging to different industries. The analysis was conducted on SmartPLS with SEM as the primary technique. The results revealed that operations management practices significantly helped in gaining competitive advantage, and supply chain management practices mediated the relationship partially. However, this research was limited to SMEs of Saudi Arabia, therefore, it can be improved in the future with the inclusion of other factors and considering other countries as well. Precisely, it is recommended that the SMEs should focus on leveraging their core competencies or identify an area which can give them a definite competitive advantage and further ensures that customer needs are translated on the product planning.
\end{abstract}

\section{Introduction}

In the current era of rapid development and advancement has made the business environment highly competitive and complex (Gamble et al., 2014). Furthermore, organisations tend to operate in a dynamic environment where a rapid surge in competition and expansion has resulted in a scarcity of resources (Barney \& Hesterly, 2010). The dynamic market environment in which certain organisations are operating exerts a greater pressure on firms regarding standards, product availability, quality, and consumer demands, and if the firms fail to address these prospects adequately, they are marginalised by the other competitors (David \& David, 2016). In this regard, in competitive business advantage holds excellent potential and central position because it can help the Small and medium-sized enterprises (SMEs) to compete with major players and create the firm position in the industry (Ates et al., 2013; Hung et al., 2015). However, competitive advantage for the organisation can only be created if the organisations invest their continuous efforts in bringing change within the firm, addressing consumer demands and managing the daily operations of their firm effectively (Herzallah et al., 2014). It has become highly crucial for organisations to enhance their operations management (OM) strategies and policies in different areas of the business to compete with the key organisations leading in a specific business sector. OM can be considered as one of the significant aspects of the organisation that helps the firm to manage their daily business tasks efficiently and achieve the organisational goals effectively (Krajewski et al., 2013). Under the study carried out by Reid and

* Corresponding author Tel.: +966554635721

E-mail address: timuniruddin@iau.edu.sa (T. Iqbal)

(C) 2020 by the authors; licensee Growing Science. doi: 10.5267 j.uscm.2020.9.001 
Sanders (2015), it was advocated that effective OM plays a crucial role in increasing the productivity of the organisation and sustainable development of the firm. However, effective OM can be considered as an imperative component for the supply chain management (SCM) system of firms because it contributes to the proper management of the products needs to manufacture and reduces the amount of wastage (Jacobs et al., 2014). Furthermore, the SCM system of any firm is closely interlinked with addressing consumer demands and ensuring product availability (Tang \& Musa, 2011; Vanichchinchai \& Igel, 2011). The study accumulated by Swink et al., (2017) implied that in the modern age, forward-looking enterprises have become dynamic, and they strive to join hands with customers, suppliers, and competitors to form the efficient supply chain system that possesses the potential of competing. In the supply chain, good operation management practices contribute significantly to transforming the raw material into valuable goods that can help the firm to generate sustainable revenue and meet rapidly changing consumer demands effectively (Sodhi et al., 2012).

Material handling, warehouse location, procurement, manufacturing, quality management, and consumer demand are some crucial functions of the supply chain that needs to be managed appropriately to ensure the execution of an efficient supply chain system in the firm (Rexhausen, 2012). In SMEs, it is essential to observe the excellent operations and SCM system because it can help them to ensure the availability of their product in the market, addressing the consumer demands on time. Furthermore, the study assembled by Wong et al. (2011) divided the operations about SCM into two different categories, such as service operations and manufacturing operations. In a survey conducted by Statista (2018) with 104 participants, $19.7 \%$ of executives responded that fluctuating consumer demands are one of the crucial challenges of the supply chain system. In the present era, almost every other small and medium enterprise, regardless of the industry they are operating in, strives for attaining the competitive advantage through innovation, change, and transforming the organisational structure (Lin et al., 2016). However, it was advocated by Solozhentsev (2015) that most of the time, a new innovative idea that was presented to create a competitive advantage and attain success for the firm gets failed easily due to weak OM of functions related to that particular idea. In the case of an innovative product, firms often fail to address the customer demands effectively result in the unavailability of product and customer disappointment that is the reflection of weak OM in the supply chain (Sorescu et al., 2011). Therefore, this research can solve this particular problem by incorporating the different prospects of $\mathrm{OM}$ and its influence on the competitive advantage of SMEs. This research aim highlights the in-depth discussion over different aspects of OM with the influence of the SCM system helps in creating a competitive advantage for the firm. This study can be considered highly beneficial for the senior management, operations, and supply chain managers of the firm because it can help them to understand the way appropriate for the management of both service and manufacturing operations in the supply chain can help their small and medium enterprise to attain the competitive advantage and stand firm in the dynamic market environment. Additionally, this study would be highly crucial for the managers of SMEs in Saudi Arabia to familiarise themselves with the significance of competitive advantage in the existing era regarding the way it is essential to take the lead among critical players of sectors. In this regard, the researcher aims to address the particular set of objectives that have been mentioned as follows:

To evaluate the significance of OM and supply chain in producing a competitive advantage for SMEs in Saudi Arabia, To evaluate the factors of OM practices and SCM system that can influence the competitive advantage,

To analyse the impact of OM practices on competitive advantage along with the mediating role of the supply chain in the case of Saudi SMEs.

In this regard, this particular study can contribute to addressing the primary research questions:

What is the impact of OM practices over competitive advantage of SMEs along with the mediating effect of SCM practices? What are the factors of OM practices and SCM that influence the competitive advantage of SMEs?

Further, this paper continues with the accumulation of literature for evaluating the key ideas of OM and competitive advantage that would help to critically evaluate the perspectives and findings of previous researchers regarding particular phenomena and add to the validity of the result. Furthermore, this research possesses the methodology section that incorporates the details regarding the way data for the particular phenomenon has been accumulated, investigated, and analysed. Next, the data analysis and discussion section of the research incorporates the investigation of data accumulated through different sources and detailed discussions to ensure that all objectives of the study have been appropriately addressed. Lastly, the conclusion has been included in the particular research along with the comprehensive summary of findings.

\section{Literature Review}

\subsection{Operations Management (OM)}

In general, $\mathrm{OM}$ is considered as the administration of the daily business tasks or practices that can assist the organisation in increasing its production rate and accomplishing the organisational goals effectively (Barratt et al., 2011; Stevenson \& Sum, 2014). Simultaneously, the study gathered by Krajewski et al., (2013) defined the phenomenon of OM as it is obligatory for all the organisations to control all the daily business as well as organisational activities seamlessly and add to the 
productivity of the firm. In most of the previous literature, there is severe ambiguity regarding the universal definition of OM because some definitions highlight the concept of function management while some studies have demonstrated the phenomenon in the context of production management (Jacobs et al., 2004; Gallindo \& Batta, 2013).

In this regard, the study accumulated by Reid and Sanders (2015) stated that controlling, managing, and executing daily functions of the firm such as routine tasks and ensure that all the activities carried out in the organisation complies with the specified standards. However, the OM in production defines the way raw materials should be manufactured, monitoring quality standards, reducing waste, and managing the consumer demands (Brown \& Bessant, 2013; Galloway et al., 2014). Similarly, while highlighting the significance of OM in the supply chain, the study accumulated by Bititci et al., (2011) asserted that majority of the activities about OM should be inclined towards manufacturing sector all aspects necessary to run the business processes smoothly that are included in the manufacturing of the specified product. The active OM plays a vital role in implementing the new ideas successfully, addressing the fluctuating consumer demands, improvising the quality standards and control the overall system of the firm in a logical manner (Howard et al., 2014; Ivanov et al., 2014). While asserting over the significance of OM Sodhi et al., (2012) advocated that it contributes to enhancing the competitive standing of the firm because appropriate management of daily business tasks can help the firm to take the lead ahead in a competitive environment.

\subsection{Supply Chain Management (SCM)}

SCM can be defined as the phenomenon of managing and controlling the process of transforming the raw material into valuable products that can create value for the organisation and add to the productivity (Seuring, 2013; Prajogo, Oke \& Olhager, 2016). Cao and Zhang (2011) asserted that the supply chain incorporates the rapid streamlining of numerous tasks of the supply side of the business that can help to achieve a competitive advantage in the business sector. Similarly, the study accumulated by Chopra et al. (2013) advocated that a sound supply chain system is essential for the manufacturing and product-oriented firms because it can be considered as the driving source for the profitability and productivity of the organisation. In studies conducted by Barney (2012) and Christopher (2016), it has been specified that excessive wastage is one of the major issues during the production process that often increases the cost of the production result in poor management of the supply chain. A supply chain is essential to manage the consumer demand by ensuring that product is always available in the market for customers and available in the location where it is required (Tayur et al., 2012; Brandenburg et al., 2014). Crum et al., (2011) and Sukati et al., (2012) stated that effective supply chain helps the organisation to attain the competitive advantage because it helps to manage the rapidly changing demands, offers the flexibility to reduce the production cost and improve the quality of the products. In this regard, most of the organisations are heading towards the adoption of different technologies such as AI, predictive analytics and big data to stabilise their supply chain system and create the competitive advantage by predicting consumer demands in advance (Guardian, 2014).

\subsection{Factors of Competitive advantage}

There are certain factors or determinants that can assist in evaluating whether a company can be competitive in the market or not. For instance, enhancement in the existing technology, producing similar products at a lower cost or similar others. However, this research particularly considers two of the main determinants, and those are improvement in the quality and the enhancement in the existing distribution network. Both of the outlined determinants underpin the OM and SCM in the context of Saudi SMEs. In this concern, they have been discussed as follows:

\subsubsection{Quality}

Quality of the product is one of the significant aspects that attract consumer attention towards a certain product and encourages them to use it regularly. Quality is the main component that has a significant impact on influencing consumer purchase decisions (Elshaer \& Augustyn, 2016). Generally, consumers are considered as the driving source of the profitability of the organisation, and if the demands of a particular product are high due to its quality, it can directly help the firm to create a competitive advantage and take the lead in the market (Herrera, 2015). Furthermore, Singh (2013) asserted that product quality helps the organisation to gain a competitive advantage because it permits to acquire a substantial market share and dominate in the market based on quality excellence. Furthermore, due to the perfect quality, the consumer demands for the product will increase in the market that can help the organisation to take the lead over its competitors (Ismail, Domil \& Isa, 2014). However, ensuring the high quality is a crucial task that can only be achieved through seamless efforts and proper management of every process of the production cycle (Goetsch \& Davis, 2014). Zhang et al. (2012) advocated that OM permits the enterprise to ensure that all the functions and production processes comply with the specified standards and delivers high quality.

\subsubsection{Distribution Network}

In supply distribution network is considered as the interconnected storage facility or central point that helps in distributing the goods and products among consumers (Stadtler, 2015; Galindo \& Batta, 2013). The distribution network holds a crucial position in ensuring product availability in the market and meeting the consumer requirement (Chopra et al., 2013; Mousavi \& Tavakkoli-Moghaddam, 2013). Barney (2012) stated that distribution networks are intermediary points that help to dissipate the product from the manufacturer side towards the consumers through retailers or direct channel. The distribution 
network is imperative to address the consumer requirement on time, and it is a crucial component for creating a competitive advantage (Marchi et al., 2013). However, improper management of supply chain activities such as delay in send products to the distribution centers and poor allocation of resources to each center can increase the rate of product unavailability in the market (Pishvaee, Rabbani \& Torabi, 2011).

\subsection{Operations Management Practices}

The OM practices are explained as the methodological solution or a procedure that is focused on shop flooring that is intended to enhance the logistic processes and efficiency of production. According to the study conducted by Bengat (2015), the author has mentioned the "WCM approach" known as the World Class Manufacturing approach that is focused on embracing comprehensive tools for conceiving to optimize professional maintenance and workplace organization. Another study conducted by Halkias (2017), highlighted TQM as the best OM practice, which helps in maintaining quality in the operations of an organization. The OM practices are discussed as,

\subsubsection{Just-in-Time Inventory (JIT)}

The JIT system is regarded as the OM strategy, which helps in aligning raw material orders from the suppliers directly with the schedules of production (Mentzer, Stank, \& Esper, 2008). Moreover, the companies mainly employ this strategy for enhancing the efficiency and bringing a reduction in the waste by receiving goods which are required for the production process (Halkias, 2017; Bengat, 2015). This procedure eventually helps the company in reducing the inventory cost and improvising the operations of the organization; however, this method requires adequate planning and forecasting of demands.

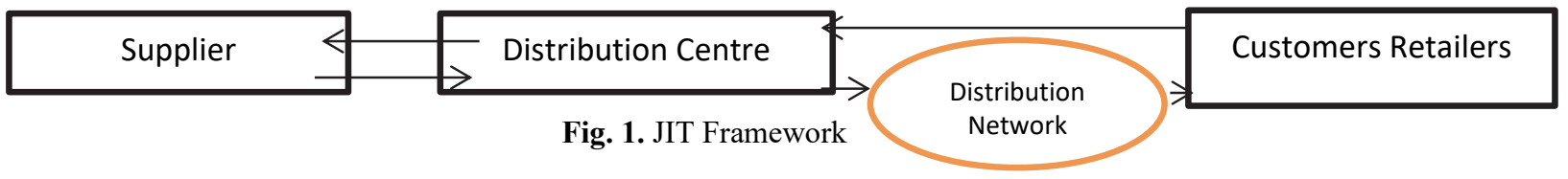

\subsubsection{Total Quality Management (TQM)}

The TQM is considered as the management framework, which is based on a belief that it can build long-term success by involving all low-level workers, executives and managerial staff to focus on improving quality and hence delivering customer satisfaction (Golicic \& Smith, 2013; Terziovski, 2010). The focus of the TQM is primarily on the continuous improvement of Kaizen principles because they are intended to bring process improvements for a more extended period and further assist in improvising operations of the company.

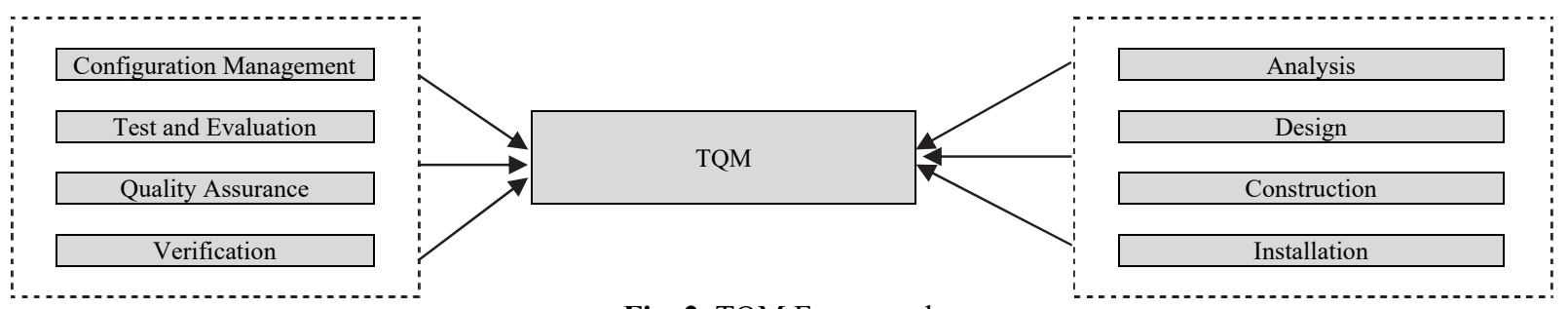

Fig. 2. TQM Framework

\subsubsection{Process and Capacity Design}

In light of study conducted by Ignaciuk and Bartoszewicz (2010), the capacity control and planning is regarded as the most important method for organising the operations of the company as it is a value-added activity which helps in achieving operating conditions for a period of time. In addition to the above statement, it is necessary to distinguish between the short and long-term capacity decisions due to fluctuations in the demand and supply of the products and services (Abran et al., 1999; Afande, Ratemo \& Nyaribo, 2015). The manufacturing of the products can be associated with the capacity and process design other than the service operations (Terziovski, 2010). Furthermore, the capacity design is mainly critical for the services as it assists in the reduction of waiting time and avoiding the sales loss due to insufficient capacity.

\subsection{Impact of Operations Management on Competitive Advantage of SMEs}

The OM plays a significant role in the practical business strategy through developing and leveraging capabilities within the domain of customers, products, and new markets (Chin, Tat \& Sulaiman, 2015; Golicic \& Smith, 2013). Moreover, the OM is based on setting competitive priorities for the company in terms of quality, delivery, flexibility, and cost. According to the study conducted by Rahman (2001), it has been highlighted that OM plays a critical role in setting competitive priorities 
as it helps in defining the market position of the firm along with manufacturing capabilities. Moreover, the OM also helps in facilitating managers with the strategic decisions which are necessary for coping up with the competition. Another study conducted by Love and Irani (2004) highlighted that OM helps in developing superior resources along with the desired outcomes that are necessary for getting a substantial edge on the competitors. The study carried out by Herzallah, GutiérrezGutiérrez and Munoz Rosas (2014) highlighted those different aspects of the OM strategy such as location planning, layout planning, and inventory control help the companies in using this strategy as the competitive weapon because it will eventually improvise the process of operations which will result in customer satisfaction. Another study carried out by Terziovski (2010), it has been highlighted that there has been significant importance of OM practices for the competitive advantage of the SMEs as such companies require strong operations strategy for the growth and development, then this is the reason that competitive advantage is supposed to be necessary for enhancing the competitive position, market share and for the growth prospects. Moreover, the managerial positions of the SMEs consider the competitive advantage as the primary determinant as it helps in creating more substantial economic value for the rivals as well as the company. A study conducted by Koh et al., (2007) highlighted that to stand out in the industry, and in other industries, SMEs must design practical competencies that are superior for the competitors and distinctive, which can only be possible with the strong operations strategy of the company.

$\mathrm{H}_{1}$ : There is a significant impact of OM on the competitive advantage of SMEs

\subsection{Mediating Role of Supply Chain between Operations Management and Competitive Advantage}

In light of the study conducted by Mentzer, Stank, and Esper (2008), it has been identified that the competitive advantage explains the extent to which a company can create a strong position among its competitors, which is only possible with effective supply chain and OM strategy. The competitive advantage helps the company in differentiating the company from its competitors by taking critical management decisions into considerations. Furthermore, it has been suggested that the constructs of SCM are directly associated with the OM and competitive advantage of the firm. The constructs are mainly related to the product quality, innovation, and timely delivery of the products and services. Also, the study conducted by Golicic and Smith (2013) highlighted that effective practices of the supply chain could help in the creation of competitive advantage for the company along with the enhanced operations performance. Moreover, the study also highlights that the supply chain improves the collaboration between the suppliers and eventually helps in bringing durable competitive edge and operations efficiency. In addition to the above statement, it has been evaluated that the practices of supply chain enhance the relationship with the customers and supplier vendors, and hence enhance the competitive advantage of the firm along with improving the operational efficiency of the company with the specific focus on the SMEs.

$\mathrm{H}_{2}$ : Supply Chain plays a mediating role in OM and competitive advantage.

\subsection{Conceptual Framework}

The conceptual framework of the research based on the literature review has been designed as follows where the dependent variable is a competitive advantage, the independent variable is OM practices, and the mediating variable is SCM practices. The variables have been further determined with the help of other metrics, as mentioned in the model:

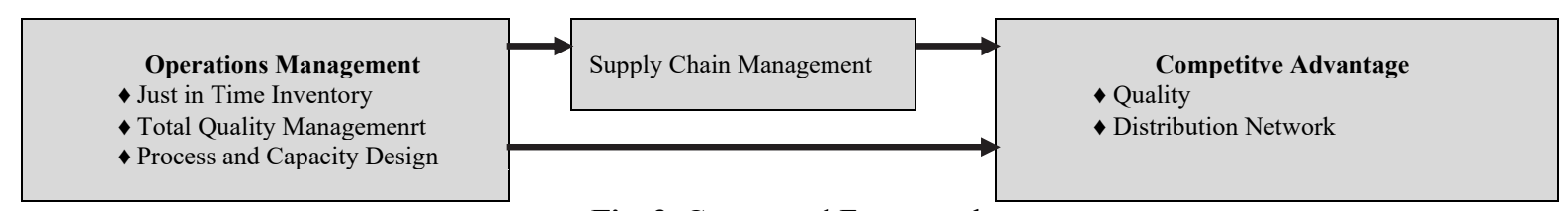

Fig. 3. Conceptual Framework

\section{Methodology}

This section clarifies the undertaken methods for the analysis purpose and justifies the selection of specific method along with the entire procedure of data collection to assessment.

\subsection{Sampling and Procedure of Data Collection}

Sampling is referred to as the process of drawing several observations from the population on which empirical investigation is conducted. In the following study, purposive and snowball sampling techniques are adopted; both are considered as nonprobability sampling techniques because the population is not given an equal chance (Wolf et al., 2016). Purposive and snowball techniques allowed the author to recruit the appropriate subjects. Probability sampling technique in this paper was difficult to adopt based on two facts; (1) the paper intended to investigate the SME's that have usually developed business position in the market with sufficient experience and (2) subjects were also matter of reliability and validity of the study since subjects were to be recruited based on specific factors such as type of business, number of employees, and annual 
turnover. Therefore, based on these considerations, the purpose sampling technique and snowball sampling technique was an appropriate selection for the study instead of any other probability sampling technique. Also, the sample should strongly reflect the aim of the study, and the sample also has to fit to represent the population as a whole. Since the population is unknown, therefore, the estimation of the sample size has been adopted from the study of Ryan (2013). The study used the following formula to determine the sample size:

$$
n=\frac{z^{2} \times p \times q}{e^{2}} \frac{(1.96)^{2} \times 0.5 \times 0.5}{(0.05)^{2}}=384
$$

In the formula, ' $z$ ' is the standard score at $95 \%$ confidence interval, and it is computed to be 1.96 . Besides, 'p' is the population proportion of the people considered as a part of this study, and it is assumed to be 0.5 whereas ' $q$ ' is the remaining proportion, which is also 0.5. In this concern, the computed sample size is 384 ; hence, the researcher approached approximately 420 participants. To further assist the aim, the research instrument used in the study was a survey questionnaire having close-ended questions. However, only 391 respondents responded appropriately while due to missing or incomplete responses, eight observations were deleted; therefore, the final sample that was used for the assessment was based on 383 participants, and it is close to the computed sample. In this case, the response rate is computed to be $91.19 \%$. The nature of the data being used in the following study is primary data collection in which the author had physically collected data from the subjects included in the sample of the study while some were approached through online channels. The respondents were briefed regarding the research aspects, and it took 15 to 20 minutes for each participant to fill the questionnaires, and overall, it consumed two months to gather the required data. Moreover, for a diverse sample, data has been accumulated from the managers and employees of different industries. The research of Morris, Panza, and Potthast (2013) explained that diversity in the sample could curb the issues of biasedness in the results. The sample is drawn with respect to the SMEs in Saudi Arabia operating in different industries in cities Riyadh, Jeddah, Dammam, Jubail, and Yanbu as follows in Table 1:

Table 1

Respondents of the Study based on Industry/ Sector

\begin{tabular}{lcc}
\hline Industry/Sector & No. of Respondents & $\%$ of Respondents \\
\hline Petrochemicals & 117 & $31 \%$ \\
Pharmaceutical & 43 & $11 \%$ \\
Electronics & 31 & $8 \%$ \\
Chemicals & 40 & $10 \%$ \\
Food and Beverages & 72 & $19 \%$ \\
Utility & 57 & $15 \%$ \\
Others & 23 & $6 \%$ \\
\hline Total & 383 & $100 \%$ \\
\hline
\end{tabular}

For the purpose of data collection, a survey questionnaire on the five-point Likert scale was developed, which contained six variables. Each variable of the study was measured through a number of questions. The data was then coded to convert it into a numerical form upon which the relevant statistical tests can be conducted.

\subsection{Data Analysis Technique}

It underpins the techniques and procedures used to conduct empirical tests to address and accomplish the research objectives (Sgier, 2012). Firstly, the reliability and validity of the constructs have been examined to determine the construct structure. Therefore, to serve the purpose, Cronbach's Alpha and composite reliability were utilised to evaluate the reliability, and for convergent validity of the latent constructs, Average Variance Extracted (AVE) was used. Meanwhile, the discriminant validity was also verified through Heterotrait-Monotrait Ratio (HTMT) to evaluate the divergent nature of the latent constructs. Besides, the paper uses confirmatory factors analysis (CFA) and path analysis as a part of Structural Equation Modelling (SEM) to test the proposed hypotheses and the hypothesised framework. SEM is one of the most popular techniques which produces robust estimations, mainly when the data is obtained from survey analysis (Kline, 2015). Initially, CFA confirms the factor structure of the latent constructs, whilst path assessment helps to determine the underconsideration relationship. In addition, this research has used SmartPLS, and PLS-SEM can be used irrespective of the underlying distribution of the data (Hair et al., 2016). Provided this, the analysis also includes demographic profiling of the respondents to comprehend the sample further.

\section{Empirical Analysis}

\subsection{Demographic Profiling}

In accordance with Fig. 4, the sample comprised $73 \%$ males and $27 \%$ females. In addition, most of the respondents belonged to the age-group ranging from 37 to 42 years, forming 32\% while the category of $18-24$ years had $14 \%$ participants, 25 to 30 years had $28 \%, 31-36$ years had 19\%, and 43 years and above had $8 \%$ participants. Concerning the education of participants, $49 \%$ were graduates, $25 \%$ were master's degree holders, $15 \%$ had a diploma, and other certifications, $9 \%$ were Ph.D., and $2 \%$ had primary or secondary level education. 


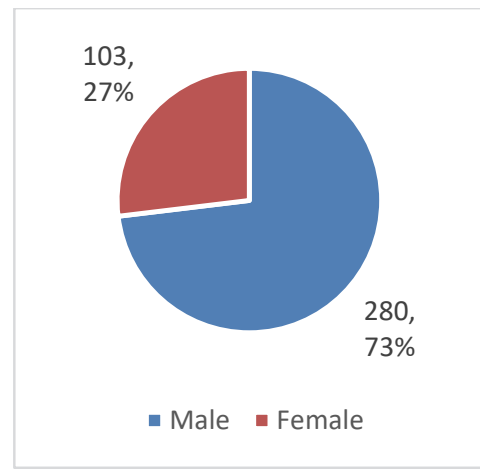

Gender

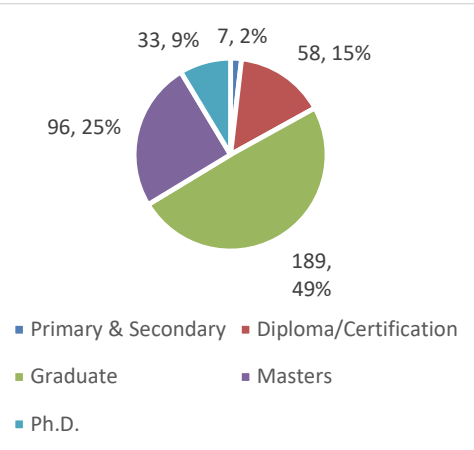

Educational background

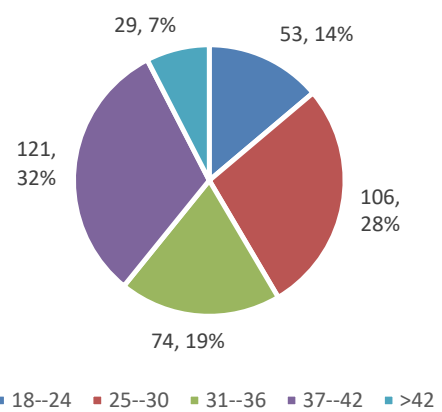

Age

Fig. 4. Personal characteristics of the participants

\subsection{Confirmatory Factor Analysis (CFA)}

The latent constructs of the study have been confirmed based on the CFA analysis, where factor loadings are examined separately. The study of Brown (2015) opined that factor loadings below 0.6 should be removed from the factor structure of the variable. In this concern, all the factors seemingly have higher factor loadings, as depicted in Table 3 . The same table also presented Cronbach Alpha and composite reliability whose thresholds, according to the study of Avkiran and Ringle (2018), are 0.6. The distribution network, JIT, process and capacity design, quality, SCM practices, and TQM are found to have $0.65,0.88,0.84,0.84,0.62$ and 0.68 reliability statistics respectively in terms of Cronbach Alpha whilst composite reliability is computed to be $0.81,0.92,0.90,0.90,0.80$ and 0.82 respectively. Also, the threshold of AVE as prescribed by the study of Essila (2019) is 0.5 . Therefore, all the mentioned constructs possess AVE above 0.5, as depicted in Table 2 .

Table 2

Testing Reliability and Convergent Validity of the Constructs

\begin{tabular}{|c|c|c|c|c|c|}
\hline Latent Constructs & Indicators & $\begin{array}{l}\text { Factor } \\
\text { Loadings }\end{array}$ & $\begin{array}{l}\text { Cronbach's } \\
\text { Alpha }\end{array}$ & $\begin{array}{l}\text { Composite } \\
\text { Reliability }\end{array}$ & $\begin{array}{l}\text { Average Variance Extracted } \\
\text { (AVE) }\end{array}$ \\
\hline \multirow[t]{3}{*}{ Distribution Network } & DN1 & $0.81 * * *$ & \multirow[t]{3}{*}{0.65} & \multirow[t]{3}{*}{0.81} & \multirow[t]{3}{*}{0.59} \\
\hline & DN2 & $0.84 * * *$ & & & \\
\hline & DN3 & $0.65 * * *$ & & & \\
\hline \multirow[t]{3}{*}{ JIT } & JIT1 & $0.86 * * *$ & \multirow[t]{3}{*}{0.88} & \multirow[t]{3}{*}{0.92} & \multirow[t]{3}{*}{0.80} \\
\hline & JIT2 & $0.91 * * *$ & & & \\
\hline & JIT3 & $0.92 * * *$ & & & \\
\hline \multirow[t]{3}{*}{ Process and Capacity Design } & PCD1 & $0.84 * * *$ & \multirow[t]{3}{*}{0.84} & \multirow[t]{3}{*}{0.90} & \multirow[t]{3}{*}{0.75} \\
\hline & PCD2 & $0.92 * * *$ & & & \\
\hline & PCD3 & $0.84 * * *$ & & & \\
\hline \multirow[t]{3}{*}{ Quality } & Q1 & $0.81 * * *$ & \multirow[t]{3}{*}{0.84} & \multirow[t]{3}{*}{0.90} & \multirow[t]{3}{*}{0.75} \\
\hline & Q2 & $0.91 * * *$ & & & \\
\hline & Q3 & $0.87 * * *$ & & & \\
\hline \multirow[t]{3}{*}{ SCM Practices } & SCM1 & $0.70 * * *$ & \multirow[t]{3}{*}{0.62} & \multirow[t]{3}{*}{0.80} & \multirow[t]{3}{*}{0.57} \\
\hline & SCM2 & $0.76^{* * *}$ & & & \\
\hline & SCM3 & $0.80 * * *$ & & & \\
\hline \multirow[t]{3}{*}{ TQM Practices } & TQM1 & $0.71 * * *$ & \multirow[t]{3}{*}{0.68} & \multirow[t]{3}{*}{0.82} & \multirow[t]{3}{*}{0.61} \\
\hline & TQM2 & $0.84 * * *$ & & & \\
\hline & TQM3 & $0.79 * * *$ & & & \\
\hline
\end{tabular}

In furtherance, the HTMT ratio is used for the determination of discriminant validity, where the maximum acceptable value is 0.9 (Dwivedi et al., 2019). In this case, Table 3 illustrates that between JIT inventory and process and capacity design, the HTMT ratio is 0.948 , which is exceeding the prescribed limit. Also, the initial assessment revealed that the effect of JIT was insignificant on specific determinants of competitive advantage. Consequently, JIT inventory was dropped from the final model. Other than this, all the values are under the threshold; therefore, other variables can be deemed as distinct.

Table 3

HTMT Ratio for Discriminant Validity

\begin{tabular}{|c|c|c|c|c|c|}
\hline & Distribution Network & JIT Inventory & Process and Capacity Design & Quality & SCM Practices \\
\hline JIT Inventory & 0.335 & & & & \\
\hline Process and Capacity Design & 0.447 & 0.948 & & & \\
\hline Quality & 0.846 & 0.337 & 0.471 & & \\
\hline SCM Practices & 0.738 & 0.242 & 0.311 & 0.630 & \\
\hline TQM Practices & 0.860 & 0.359 & 0.383 & 0.594 & 0.779 \\
\hline
\end{tabular}


The path assessment has been conducted in segments where the direct effect was tested firstly, and the indirect effect was tested later, and the total effect was computed in the end. According to Table 4, the direct effect of process and capacity design is computed to be statistically significant on the distribution network $(B=0.140 ; p$-value $=0.001<0.01)$ and similar is the case with quality $(\mathrm{B}=0.265 ; \mathrm{p}$-value $=0.000<0.01)$. In addition, the effect of process and capacity design is computed to be positively significant on SCM practices $(B=0.097$; $\mathrm{p}$-value $=0.027<0.05)$. The effect of SCM practices on distribution network of Saudi Arabian SMEs is significant as well $(B=0.243$; $p$-value $=0.001<0.01)$ along with quality $(B=0.285 ; p$ value $=0.000<0.01)$. Lastly, the effect of TQM on distribution network $(B=0.414 ; p$-value $=0.000<0.01)$, quality $(B=$ 0.237 ; p-value $=0.000<0.01)$ and SCM practices $(B=0.476$; $p$-value $=0.000<0.01)$ is computed to be significant and positive. The positive coefficients imply that improvement in the operations' management of SMEs in Saudi Arabia can lead the companies towards attaining a competitive edge in the market, and in this manner, they may become able to compete with the rival multinational companies in the long-run.

Table 4

Assessment of Direct Effect

\begin{tabular}{|c|c|c|c|}
\hline Direct Effect & Path Coefficient & T Statistics & P Values \\
\hline Process and Capacity Design $\rightarrow$ Distribution Network & $0.140^{* * *}$ & 3.209 & 0.001 \\
\hline Process and Capacity Design $\rightarrow$ Quality & $0.265 * * *$ & 5.036 & 0.000 \\
\hline Process and Capacity Design $\rightarrow$ SCM Practices & $0.097 * *$ & 2.221 & 0.027 \\
\hline SCM Practices $\rightarrow$ Distribution Network & $0.243 * * *$ & 3.408 & 0.001 \\
\hline SCM Practices $\rightarrow$ Quality & $0.285 * * *$ & 4.178 & 0.000 \\
\hline TQM $\rightarrow$ Distribution Network & $0.414 * * *$ & 7.540 & 0.000 \\
\hline TQM $\rightarrow$ Quality & $0.237 * * *$ & 4.184 & 0.000 \\
\hline $\mathrm{TQM} \rightarrow \mathrm{SCM}$ Practices & $0.476^{* * *}$ & 9.608 & 0.000 \\
\hline
\end{tabular}

The mediation has been examined with the help of the indirect effect of OM practices as independent constructs on the competitive advantage as the dependent constructs through the mediating variable, which is SCM practices. The results in Table 5 assert that the indirect effect of process and capacity design on the distribution network is statistically significant and positive $(B=0.023$; $p$-value $=0.096<0.1)$. Similarly, process and capacity design's effect on quality is also significant and positive through $\mathrm{SCM}$ practices $(\mathrm{B}=0.116$; $\mathrm{p}$-value $=0.004<0.01)$. In addition, the effect of TQM through $\mathrm{SCM}$ practices on distribution network and quality is statistically significant with $(B=0.028 ; p$-value $=0.067<0.1)$ and $(B=0.136$; $\mathrm{p}$-value $=0.000<0.01)$ respectively. Overall, partial mediation is found, which is positive as well, because both direct and indirect effects are significant.

Table 5

Testing the Indirect Effect

\begin{tabular}{|c|c|c|c|}
\hline Indirect Effect & Path Coefficient & T Statistics & P Values \\
\hline Process and Capacity Design $\rightarrow$ SCM Practices $\rightarrow$ Distribution Network & $0.023^{*}$ & 1.667 & 0.096 \\
\hline $\mathrm{TQM} \rightarrow$ SCM Practices $\rightarrow$ Distribution Network & $0.116^{* * *}$ & 2.868 & 0.004 \\
\hline Process and Capacity Design $\rightarrow$ SCM Practices $\rightarrow$ Quality & $0.028 *$ & 1.836 & 0.067 \\
\hline TQM $\rightarrow$ SCM Practices $\rightarrow$ Quality & $0.136 * * *$ & 3.506 & 0.000 \\
\hline
\end{tabular}

In accordance with Table 6, the model is confirmed to have both direct and indirect effects, and this implies that SCM practices partially mediate the association between OM and competitive advantage. The inference has been drawn based on significant total effects.

Table 6

Total Effects' Assessment

\begin{tabular}{|c|c|c|c|}
\hline Total Effect & Path Coefficient & T Statistics & P Values \\
\hline Process and Capacity Design -> Distribution Network & $0.164 * * *$ & 3.624 & 0.000 \\
\hline Process and Capacity Design -> Quality & $0.293 * * *$ & 5.798 & 0.000 \\
\hline TQM -> Distribution Network & $0.530 * * *$ & 15.587 & 0.000 \\
\hline TQM-> Quality & $0.373 * * *$ & 9.463 & 0.000 \\
\hline
\end{tabular}

There were two main models where the first one was an internal model, and the quality of these models have been evaluated in Table 8 . In this case, the variance explained by process and capacity design and TQM was $26.3 \%$ variance in SCM practices, and after the adjustment of errors, it was reduced to $25.9 \%$. In the case of outer models, the variance explained by process and capacity design, and TQM along with the moderating effect of SCM practices, is $40.2 \%$ in the distribution network and $34.8 \%$ in quality. Comparatively, the variance explanation of model with distribution network as the dependent variable is found to be better than the one with quality as dependent variable based on adjusted R-squared that are $39.7 \%$ and $34.3 \%$, respectively, as depicted in Table 7 as follows. 
Table 7

Quality Analysis of the Models

\begin{tabular}{lcc} 
& R Square & R Square Adjusted \\
\hline Distribution Network & $40.2 \%$ & $39.7 \%$ \\
Quality & $34.8 \%$ & $34.3 \%$ \\
SCM Practices & $26.3 \%$ & $25.9 \%$ \\
\hline
\end{tabular}

\subsection{Hypotheses Assessment Summary}

Initially, two hypotheses were proposed, and both are accepted in accordance with the conducted study. Besides, the mediation is computed to be partial. The summary has been presented in Table 8 .

Table 8

Analysis Summary of the Hypotheses

\begin{tabular}{ll}
\hline Propositions & Result \\
\hline H1: There is a significant impact of OM on the competitive advantage of SMEs & Accepted \\
H2: Supply Chain plays a mediating role between OM and competitive advantage & Accepted [Partial Mediation is found] \\
\hline
\end{tabular}

\section{Discussion}

The research was focused on evaluating the impact of OM practices for SMEs on competitive advantage. Moreover, the results identified the essential OM practices which are necessary for improvising the competitive advantage of the firm. In this research, the data was collected through SMEs and then analysed with the SEM approach with the model developed for analysing the influence of variables. Based on the results, a positive association was identified between OM practices on the competitive advantage of the SMEs. Moreover, a moderating effect was also identified as SCM on the OM practices and the competitive advantage. This offers a clear case of input for the OM practices for the competitive advantage. Based on the findings, it can be deduced that SMEs can implement the OM practices for improving the competitive advantage successfully, and this would possibly help the company in enhancing the number of consumers with increment in the market share. The results are in line with the study conducted by Barney (2012), who has highlighted that the effective adoption of OM practices will help the company to gain a strong competitive position in the industry and will further be able to cope with the challenges and changes. In addition to the above statement, the supply chain hence plays an integral part in the OM and building a definite competitive advantage of the companies. Hence, it is recommended that SME managers should focus on developing a strong plan which serves as the guidelines for the employees for having a sustainable competitive advantage.

\section{Practical and Theoretical Significance}

The findings carried out from this study have assisted the researcher in both practical and theoretical significance. Moreover, the research highlights the significant importance of the OM practices for SMEs with a specific focus on the manufacturing sector. Moreover, the OM practices which are relevant should be taken into account by the management for implementing best practices that can influence the operations efficiency and competitive advantage of the company. Besides, the findings of the study also reflect on clear input as to how the businesses should implement the diffusion of OM culture for the business clusters where new policies should be implemented to retain a durable competitive edge in the company. In addition to the above statement, the results were also consistent with the previous studies which focus on the investigation of the relation between OM, competitive advantage, and SCM. Furthermore, for the practical significance of the study, the research will be significant for the SMEs who want to improvise their performances in terms of operations to sustain their competitive advantage. Since it is a known fact that SMEs are at the growing stages, therefore, the companies must take appropriate actions for ensuring appropriate performance in terms of supply chain activities and OM. In terms of the theoretical significance, the following study has focused on the contribution of the understanding of the concepts associated with competitive advantage and OM. Moreover, different OM practices were identified that would assist the SMEs in effectively implementing in the company. Precisely, the research study helped in understanding that most preferred competitive priority is based on selecting an effective operations strategy.

\section{Limitations and Future Research}

The present study has significantly provided practical and theoretical contributions that are focused on the concept of OM and SCM, which are applicable in the SMEs. However, certain limitations are necessary to identify where the first limitation is pertaining to the sample size, which has been undertaken for this study. This could be improved to bring further effectiveness and authenticity in the results. The second limitation is associated with the generalizability of the SMEs, which are taken into consideration for this study. Finally, the results which are gathered for this study are only limited for the quantitative findings, where the survey was carried out from the owners of the SMEs. However, this can also be achieved through the qualitative research design by interviewing supply chain managers along with the operations managers who can 
provide valuable insights into the research phenomenon. Future researchers could have a look by taking into focus the qualitative perspective to authenticate the findings of the study. Also, a contrasting opinion can be added where the developed and developing countries can be compared for the research area, which is under discussion here. In furtherance, this research has considered only two dimensions of competitive advantage, and those are quality and distribution networks. Therefore, future researchers can consider other dimensions like change in technology, cost, and similar other aspects.

\section{Conclusion}

This research paper has focused on analysing the influence of OM practices on the competitive advantage of SMEs with the mediating effects of SCM. The research mainly concludes that the companies should prioritise the OM strategies for having a sustainable competitive advantage. The SMEs should improve the experience of the customers by having a sustainable edge over the competitors and providing quality services which can only be possible by having effective OM and SCM strategies. In addition, the SMEs should also focus on leveraging their core competencies or identify an area which can give them a strong competitive advantage and further ensures that customer needs are translated on product planning.

\section{References}

Abran, A., Laframboise, L., \& Bourque, P. (1999). A risk assessment method and grid for software measurement programs. Rapport technique, (99-03).

Afande, F. O., Ratemo, B. M., \& Nyaribo, F. N. (2015). Adoption of supply chain management practices: Review of determining factors. Innovative Systems Design and Engineering, 6(5), 72-77.

Ates, A., Garengo, P., Cocca, P. \& Bititci, U., (2013). The development of SME managerial practice for effective performance management. Journal of Small Business and Enterprise Development, 20(1), 28-54.

Avkiran, N., \& Ringle, C. (2018). Partial least squares structural equation modeling. Handbook of Market Research (Vol. 267).

Barney, J.B. \& Hesterly, W.S., (2010). Strategic management and competitive advantage: Concepts and cases (4-25). Upper Saddle River, NJ: Prentice Hall.

Barney, J.B., (2012). Purchasing, supply chain management and sustained competitive advantage: The relevance of resource-based theory. Journal of supply chain management, 48(2), 3-6.

Barratt, M., Choi, T.Y. \& Li, M., (2011). Qualitative case studies in operations management: Trends, research outcomes, and future research implications. Journal of Operations Management, 29(4), 329-342.

Bengat, N. J. (2015). Operations Management Practices and Performance of Agricultural Non-Governmental Organizations in Nairobi County (Doctoral dissertation, University of Nairobi).

Bititci, U.S., Ackermann, F., Ates, A., Davies, J.D., Gibb, S., MacBryde, J., Mackay, D., Maguire, C., Van der Meer, R. \& Shafti, F., (2011). Managerial processes: an operations management perspective towards dynamic capabilities. Production Planning and Control, 22(2), 157-173.

Brandenburg, M., Govindan, K., Sarkis, J. \& Seuring, S., (2014). Quantitative models for sustainable supply chain management: Developments and directions. European Journal of Operational Research, 233(2), 299-312.

Brown, S. \& Bessant, J., (2013). Strategic operations management. Routledge.

Brown, T. A. (2015). Confirmatory factor analysis for applied research. Guilford publications.

Cao, M. \& Zhang, Q., (2011). Supply chain collaboration: Impact on collaborative advantage and firm performance. Journal of Operations Management, 29(3), 163-180.

Chin, T. A., Tat, H. H., \& Sulaiman, Z. (2015). Green supply chain management, environmental collaboration and sustainability performance. Procedia Cirp, 26, 695-699.

Chopra, S., Meindl, P. \& Kalra, D.V., (2013). Supply chain management: strategy, planning, and operation (Vol. 232). Boston, MA: Pearson.

Christopher, M., (2016). Logistics \& supply chain management. Pearson UK.

Crum, M., Poist, R., Carter, C.R. \& Easton, P.L., (2011). Sustainable supply chain management: evolution and future directions. International journal of physical distribution \& logistics management, 12(1), 12-36.

David, F. \& David, F.R., (2016). Strategic management: A competitive advantage approach, concepts and cases. PearsonPrentice Hall.

Dwivedi, Y., Ayaburi, E., Boateng, R., \& Effah, J. (2019). ICT Unbounded, Social Impact of Bright ICT Adoption. Springer International Publishing.

Elshaer, I.A. \& Augustyn, M.M., (2016). Direct effects of quality management on competitive advantage. International Journal of Quality \& Reliability Management.

Essila, J. C. (Ed.). (2019). Managing Operations Throughout Global Supply Chains. IGI Global.

Galindo, G. \& Batta, R., (2013). Review of recent developments in OR/MS research in disaster operations management. European Journal of Operational Research, 230(2), 201-211.

Galloway, L., Rowbotham, F. \& Azhashemi, M., (2012). Operations management in context. Routledge.

Gamble, J.E., Peteraf, M.A. \& Thompson, A.A., (2014). Essentials of strategic management: The quest for competitive advantage. McGraw-Hill Education. 
Gilal, F. G., Zhang, J., Gilal, R. G., Gilal, R. G., \& Gilal, N. G. (2017). Supply chain management practices and product development: a moderated mediation model of supply chain responsiveness, organization structure, and research and development. Journal of Advanced Manufacturing Systems, 16(01), 35-56.

Goetsch, D.L. \& Davis, S.B., (2014). Quality management for organizational excellence. Upper Saddle River, NJ: pearson.

Golicic, S. L., \& Smith, C. D. (2013). A meta-analysis of environmentally sustainable supply chain management practices and firm performance. Journal of Supply Chain Management, 49(2), 78-95.

Guardian. (2014). Why big data will have a big impact on sustainability. Available at: https://www.theguardian.com/sustainable-business/big-data-impact-sustainable-business (Accessed: 6 February 2020).

Hair Jr, J. F., Hult, G. T. M., Ringle, C., \& Sarstedt, M. (2016). A primer on partial least squares structural equation modeling (PLS-SEM). Sage publications.

Halkias, D. (2017). Characteristics and Business Profiles of ImmigrantOwned Small Firms: The Case of Albanian Immigrant Entrepreneurs in Greece.

Herrera, M.E.B., (2015). Creating competitive advantage by institutionalizing corporate social innovation. Journal of Business Research, 68(7), 1468-1474.

Herzallah, A. M., Gutiérrez-Gutiérrez, L., \& Munoz Rosas, J. F. (2014). Total quality management practices, competitive strategies and financial performance: the case of the Palestinian industrial SMEs. Total Quality Management \& Business Excellence, 25(5-6), 635-649.

Howard, M., Caldwell, N., Smith, L., Maull, R. \& Ng, I.C., (2014). Servitization and operations management: a service dominant-logic approach. International Journal of Operations \& Production Management.

Hung, S.C., Hung, S.W. \& Lin, M.J.J., (2015). Are alliances a panacea for SMEs? The achievement of competitive priorities and firm performance. Total Quality Management \& Business Excellence, 26(1-2), 190-202

Ignaciuk, P., \& Bartoszewicz, A. (2010, August). Composite control of periodic-review just-in-time inventory systems with asymmetric costs. In 2010 15th International Conference on Methods and Models in Automation and Robotics (pp. 16). IEEE.

Ismail, M. D., Domil, A. A., \& Isa, A. M. (2014, February). Managerial competence, relationship quality and competitive advantage among SME exporters. In Procedia-Social and Behavioral Sciences (Vol. 115, No. 1, 138-146). Elsevier.

Ivanov, D., Tsipoulanidis, A. \& Schönberger, J., (2017). Global supply chain and operations management. A DecisionOriented Introduction to the Creation of Value.

Jacobs, F.R., Chase, R.B. \& Aquilano, N.J., (2004). Operations management for competitive advantage. Boston: Mc-Graw Hill, 64, 70 .

Jacobs, F.R., Chase, R.B. \& Lummus, R.R., (2014). Operations and supply chain management (533-535). New York, NY: McGraw-Hill/Irwin.

Kline, R. B. (2015). Principles and practice of structural equation modeling. Guilford publications.

Koh, S. L., Demirbag, M., Bayraktar, E., Tatoglu, E., \& Zaim, S. (2007). The impact of supply chain management practices on performance of SMEs. Industrial Management \& Data Systems.

Krajewski, L.J., Ritzman, L.P. \& Malhotra, M.K., (2013). Operations management. Pearson Education UK.

Lin, H.F., Su, J.Q. \& Higgins, A., (2016). How dynamic capabilities affect adoption of management innovations. Journal of Business Research, 69(2), 862-876.

Love, P. E., \& Irani, Z. (2004). An exploratory study of information technology evaluation and benefits management practices of SMEs in the construction industry. Information \& Management, 42(1), 227-242.

Marchi, V.D., Maria, E.D. \& Micelli, S., (2013). Environmental strategies, upgrading and competitive advantage in global value chains. Business strategy and the environment, 22(1), 62-72.

Mentzer, J. T., Stank, T. P., \& Esper, T. L. (2008). Supply chain management and its relationship to logistics, marketing, production, and operations management. Journal of business logistics, 29(1), 31-46.

Morris, T., Panza, C., \& Potthast, A. (2013). Philosophy \& Ethics For Dummies 2 eBook Bundle: Philosophy For Dummies \& Ethics For Dummies. John Wiley \& Sons.

Mousavi, S. M., \& Tavakkoli-Moghaddam, R. (2013). A hybrid simulated annealing algorithm for location and routing scheduling problems with cross-docking in the supply chain. Journal of Manufacturing Systems, 32(2), 335-347.

Pishvaee, M. S., Rabbani, M., \& Torabi, S. A. (2011). A robust optimization approach to closed-loop supply chain network design under uncertainty. Applied Mathematical Modelling, 35(2), 637-649.

Prajogo, D., Oke, A., \& Olhager, J. (2016). Supply chain processes. International Journal of Operations \& Production Management, 36(2), 220-238

Rahman, S. U. (2001). A comparative study of TQM practice and organisational performance of SMEs with and without ISO 9000 certification. International Journal of Quality \& Reliability Management, 27(9), 1021-1035

Reid, R.D. \& Sanders, N.R., (2015). Operations management: an integrated approach. John Wiley \& Sons.

Rexhausen, D., Pibernik, R. \& Kaiser, G., (2012). Customer-facing supply chain practices-The impact of demand and distribution management on supply chain success. Journal of Operations Management, 30(4), 269-281.

Ryan, T. P. (2013). Sample size determination and power. John Wiley \& Sons.

Seuring, S., (2013). A review of modeling approaches for sustainable supply chain management. Decision support systems, 54(4), 1513-1520.

Sgier, L. (2012). Qualitative data analysis. An Initiat. Gebert Ruf Stift, 19, 19-21.

Singh, M. (2013). Product Quality for Competitive Advantage in Marketing. International Journal of Business and Management Invention, 2(6), 05-08. 
Sodhi, M.S., Son, B.G. \& Tang, C.S., (2012). Researchers' perspectives on supply chain risk management. Production and operations management, 21(1), 1-13.

Solozhentsev, E.D. (2015). Logic and probabilistic risk models for management of innovations system of country. International Journal of Risk Assessment and Management, 18(3-4), 237-255.

Sorescu, A., Frambach, R.T., Singh, J., Rangaswamy, A. \& Bridges, C., (2011). Innovations in retail business models. Journal of Retailing, 87, S3-S16.

Stadtler, H. (2015). Supply chain management: An overview. In Supply chain management and advanced planning ( 3-28). Springer, Berlin, Heidelberg.

Statista. (2018). Supply chain industry: biggest challenges 2018. Available at: https:/www.statista.com/statistics/829634/biggest-challenges-supply-chain/ (Accessed: 6 February 2020).

Stevenson, W. J., \& Sum, C. C. (2014). Operations management (Vol. 10). New York, NY: McGraw-Hill/Irwin.

Sukati, I., Hamid, A. B., Baharun, R., \& Yusoff, R. M. (2012). The study of supply chain management strategy and practices on supply chain performance. Procedia-Social and Behavioral Sciences, 40, 225-233.

Swink, M., Melnyk, S.A., Hartley, J.L. \& Cooper, M.B., (2017). Managing operations across the supply chain. New York, NY: McGraw-Hill Education.

Tang, O. \& Musa, S.N., (2011). Identifying risk issues and research advancements in supply chain risk management. International journal of production economics, 133(1), 25-34.

Tayur, S., Ganeshan, R. \& Magazine, M. eds., (2012). Quantitative models for supply chain management (Vol. 17). Springer Science \& Business Media.

Terziovski, M. (2010). Innovation practice and its performance implications in small and medium enterprises (SMEs) in the manufacturing sector: a resource-based

Vanichchinchai, A. \& Igel, B., (2011). The impact of total quality management on supply chain management and firm's supply performance. International Journal of Production Research, 49(11), 3405-3424.

Wolf, C., Joye, D., Smith, T. W., \& Fu, Y. C. (Eds.). (2016). The SAGE handbook of survey methodology. Sage.

Wong, C.Y., Boon-Itt, S. \& Wong, C.W., (2011). The contingency effects of environmental uncertainty on the relationship between supply chain integration and operational performance. Journal of Operations Management, 29(6), 604-615.

Zhang, D., Linderman, K. \& Schroeder, R.G., (2012). The moderating role of contextual factors on quality management practices. Journal of Operations Management, 30(1-2), 12-23. 


\section{Appendices}

\section{Appendix A: Questionnaire}

Name:

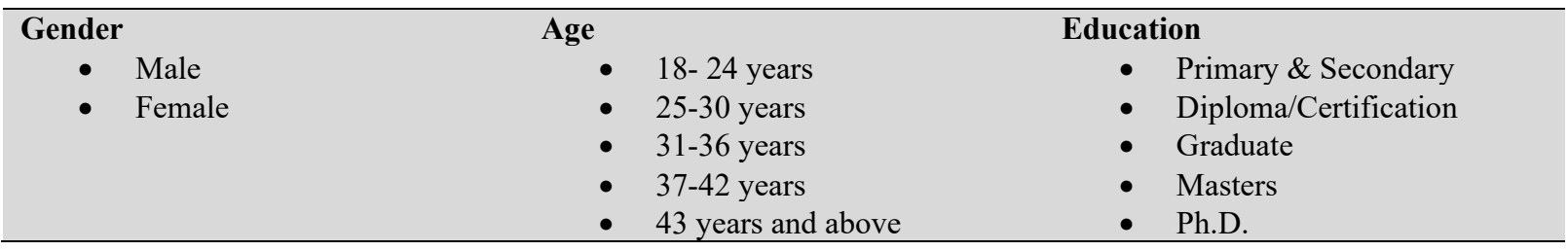

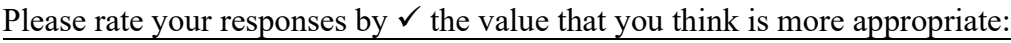

\begin{tabular}{|c|c|c|c|c|c|c|c|c|}
\hline \multirow{2}{*}{$\begin{array}{l}\text { Strongly Agree (SA) } \\
5 \\
\end{array}$} & \multirow{2}{*}{$\begin{array}{l}\text { Agree (A) } \\
4 \\
\end{array}$} & \multirow{2}{*}{$\begin{array}{l}\text { Neutral (N) } \\
3 \\
\end{array}$} & \multirow{2}{*}{$\begin{array}{l}\text { Disagree (D) } \\
2 \\
\end{array}$} & \multicolumn{5}{|c|}{ Strongly Disagree (SD) } \\
\hline & & & & \multicolumn{5}{|l|}{1} \\
\hline Questions & & & & SA & A & $\mathrm{N}$ & $\mathrm{D}$ & SD \\
\hline \multicolumn{9}{|c|}{ Operations Management Practices } \\
\hline \multicolumn{9}{|l|}{ JIT } \\
\hline \multicolumn{9}{|c|}{ Intolerance to waste and non-value added activities } \\
\hline \multicolumn{9}{|c|}{ Inventory Reduction at every stage } \\
\hline \multicolumn{9}{|l|}{ It helps in Cost-cutting } \\
\hline \multicolumn{9}{|l|}{ TQM } \\
\hline \multicolumn{9}{|c|}{ Continuous improvement in Processes } \\
\hline \multicolumn{9}{|c|}{ Process improvement and simplification } \\
\hline \multicolumn{9}{|c|}{ Employee involvement in process improvement } \\
\hline \multicolumn{9}{|c|}{ Process and Capacity Design } \\
\hline \multicolumn{9}{|c|}{ Serves as the value-added activity } \\
\hline \multicolumn{9}{|c|}{ Distinguish between short and long-term capacity decisions } \\
\hline \multicolumn{9}{|c|}{ Reduction of waiting time and avoiding the sales loss } \\
\hline \multicolumn{9}{|l|}{ Competitive Advantage } \\
\hline \multicolumn{9}{|l|}{ Quality } \\
\hline \multicolumn{9}{|c|}{ Improved processes for customers } \\
\hline \multicolumn{9}{|c|}{ Compliance with the specified standards and delivers high quality. } \\
\hline \multicolumn{9}{|c|}{ Products are of high quality } \\
\hline \multicolumn{9}{|l|}{ Distribution Network } \\
\hline \multicolumn{9}{|c|}{ Effectiveness of the supply distribution network } \\
\hline \multicolumn{9}{|l|}{ Product Availability } \\
\hline \multicolumn{9}{|l|}{ Timely product delivery } \\
\hline \multicolumn{9}{|c|}{ Supply Chain Management } \\
\hline \multicolumn{9}{|c|}{ Managing consumer demand by ensuring product availability. } \\
\hline Supply chain helps in & ing competi & & & & & & & \\
\hline Helps in improving pro & uality. & & & & & & & \\
\hline
\end{tabular}

\section{Appendix B: Models}

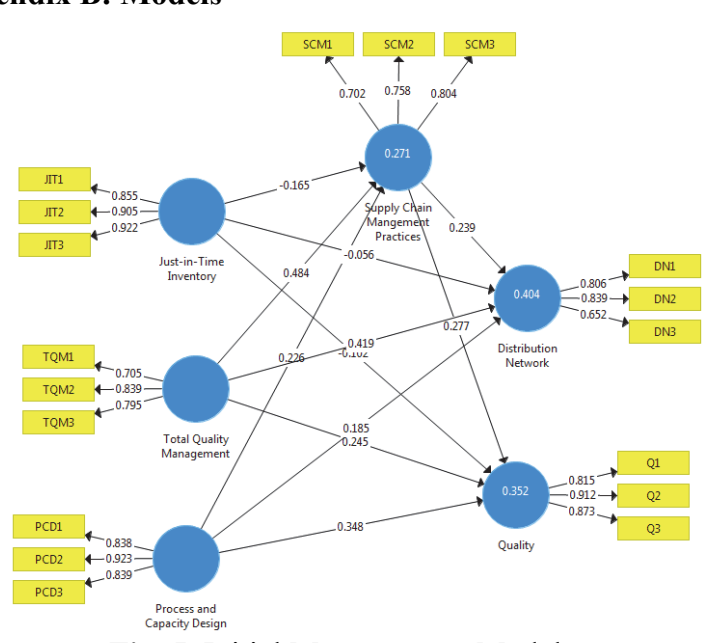

Fig. 5. Initial Measurement Model

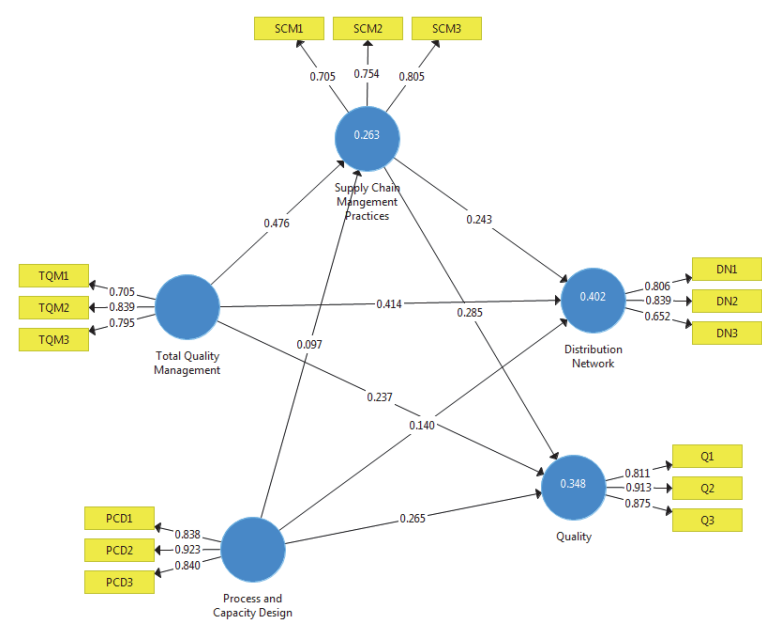

Fig. 6. Final Measurement Model 


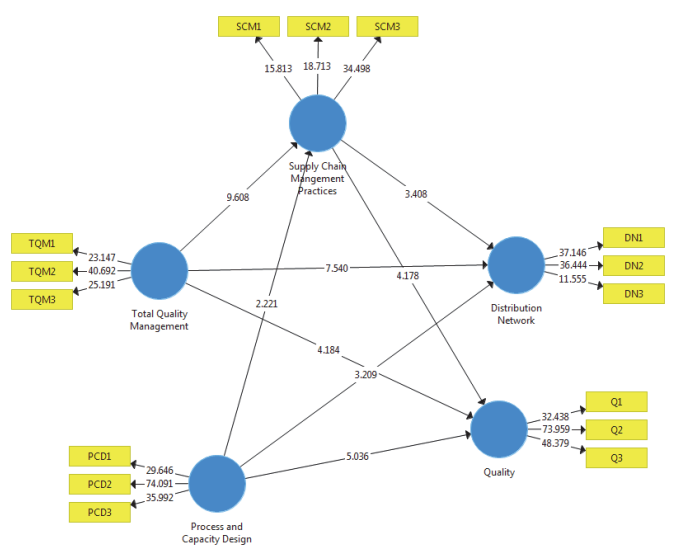

Fig. 7. Model after Bootstrapping with T-statistics

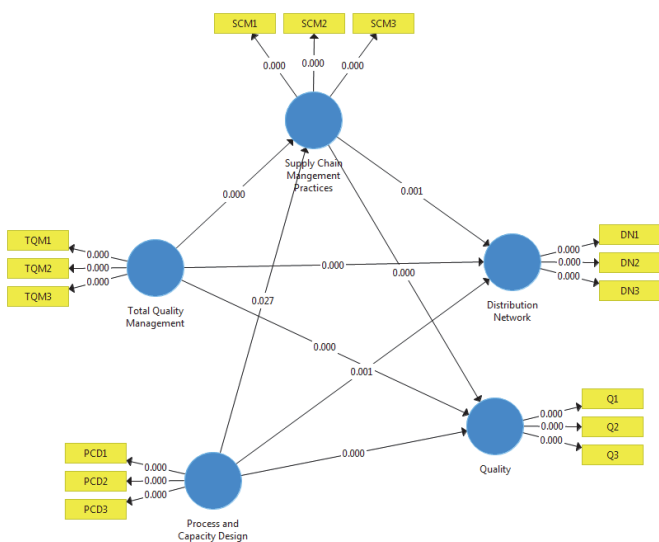

Fig. 8. Model after Bootstrapping with p-values

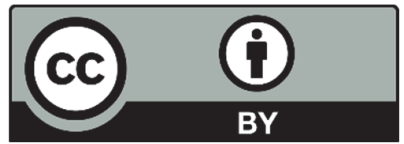

(C) 2020 by the authors; licensee Growing Science, Canada. This is an open access article distributed under the terms and conditions of the Creative Commons Attribution (CC-BY) license (http://creativecommons.org/licenses/by/4.0/). 